\title{
Influence of individual psychophysical characteristics of the worker on electrical accidents
}

\author{
Gennady Lebedev ${ }^{1}$, Sergey Zakharov ${ }^{1}$, Sergey Zakharenko ${ }^{1}$, Vladimir Sytnik ${ }^{1 *}$, and Raisa \\ Zakharova $^{1}$ \\ ${ }^{1}$ T.F. Gorbachev Kuzbass State Technical University, 650000, 28, Vesennyaya st., Kemerovo, \\ Russian Federation
}

\begin{abstract}
The article discusses the risks and factors of electrical safety that affect the working person. Electrical injury, in comparison with other types of industrial injuries, is a relatively small percentage, however, in terms of the number of injuries with severe and fatal outcomes it takes the leading place. That is why the utmost attention must be paid to the issues of electrical safety. You need to understand how electric current affects the human body, the conditions for falling under dangerous voltage, measures to protect against electric shock. The article is of great practical importance both for those interested in electrical safety issues and for employees of enterprises in the mining and energy industries.
\end{abstract}

\section{Introduction}

Preserving the life and health of employees of the organization is a priority direction of state policy, therefore, it is necessary to carry out systematic work in the field of labor protection, aimed at reducing the risks of injury and occupational morbidity.

Specific professional risks for enterprises using electrical equipment in the technological process, including mining enterprises, the most serious of which is the danger of exposure to electric current, make it necessary for employers to build a strict policy of unswerving compliance with all types of labor protection requirements, production and labor discipline by all workers.

In the past decade, the fatal injury rate in Russia has generally remained high. But according to the latest data, there is a positive trend in the reduction of occupational injuries. This suggests that the work carried out by enterprises is going in the right direction.

At any power plant, the main traumatic factor is electric shock. Consider the causes of accidents.

The main causes of accidents are:

- electric shock

- fall of the injured person (victim) from a height;

- the impact of rotating, flying away, moving objects, parts, machines and mechanisms.

\footnotetext{
${ }^{*}$ Corresponding author: $\underline{\text { sytnikva } @ \text { kuzstu.ru }}$
} 
The main factors of the causes of accidents can be represented in Figure 1.

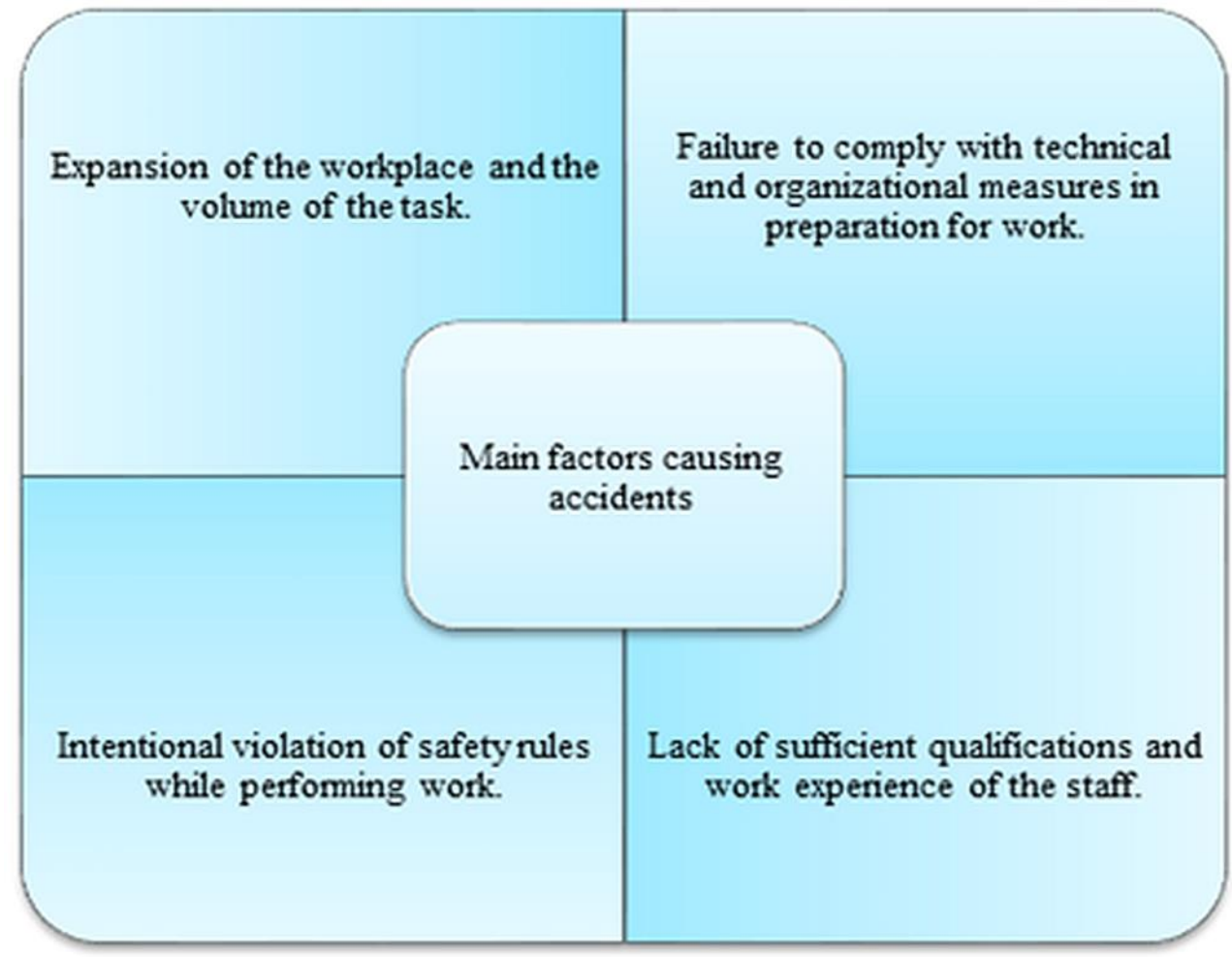

Fig. 1. Main factors causing accidents

Assessment of risks, dangers and their identification is a priority task in the fight against electrical injuries, these skills allow you to learn how to manage these risks, form the skills of workers to determine the main production risks.

When assessing possible risks, it is necessary to proceed from the severity of the consequences and measures to control them. Control measures should be commensurate with the risk.

Should be considered:

- what risks can be eliminated?

- what risks can be managed?

- what effective measures can be taken?

Key risk management measures:

- full compliance with instructions and rules;

- use of PPE;

- observance of labor discipline;

- self-control and mutual control.

The main principles for identifying and eliminating risk:

- perform a risk assessment;

- develop and take measures to eliminate the risk;

- if it is impossible to eliminate the risk, it is necessary to take measures for individual or collective protection. 


\section{Results}

According to statistics, the frequency of occurrence of situations, which can lead to injury, can be represented in the form of a pyramid. The principle is described in the theory of $F$. Byrd. It can be concluded that ensuring labor safety is counteraction at the source of risk.

In addition, there is the Bradley Curve - an effective tool in improving occupational safety. According to this pattern, the more joint efforts are made to ensure electrical safety, the less the likelihood of accidents. Employees must ensure that work is carried out safely, not only under the influence of instinct and management supervision, but also by being proactive, both personally and as a team.

Common acute consequences of electrical injury are known. Electric shock often causes a phobia of electric shock, which lasts up to several years. In this case, psychogenic reactions, confusion, self-doubt, disturbances in visual perception can manifest themselves.

The risks of developing dizziness, migraine, and epilepsy in the long term increase [1].

Peripheral autonomic syndromes can be observed:

-local cyanosis;

- anhidrosis;

- memory disorders;

-hyperhidrosis;

-emotional and vegetative lability.

It is observed that recently there are data that the development of amyotrophic lateral sclerosis can be associated with episodes of electrical trauma [2]. At the same time, the hypothesis of provoking Parkinson's disease with electric shock has not yet been confirmed. But there is data on the delayed consequences of an electric shock - for example, it has been shown that degeneration of a motor neuron is possible - and, moreover, after a fairly long time. The average delay in the onset of motor neuron disease was 44 months. The disease progressed relatively slowly.

There is a need to develop a different principled approach to the analysis of systems "man - electrical installation" [3].

Let us present the factors influencing a working person in the form of Figure 2.

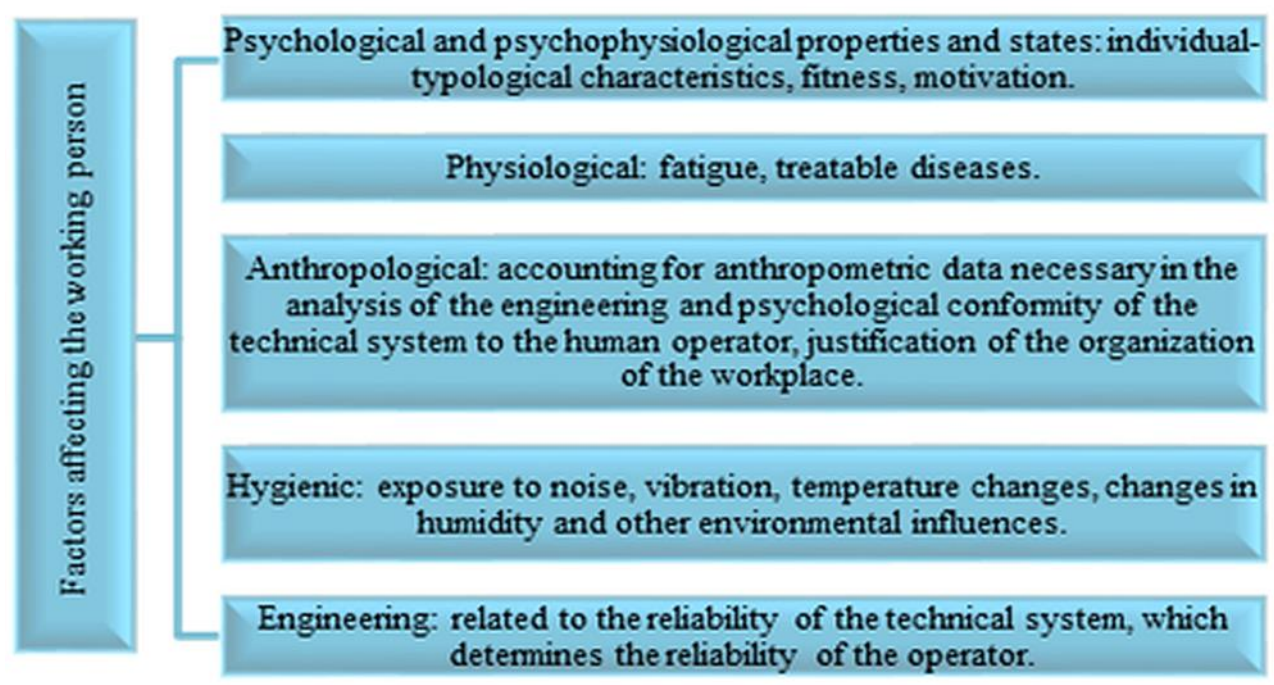

Fig. 2. Factors affecting the working person 
When selecting for work in such enterprises, where work is based on the "manmachine" system, and especially if the work is associated with responsibility and a threat to life, one should carefully consider the mental state of the person.

Violations in the emotional-volitional sphere, character anomalies are called "psychopathies" (Fig. 3).

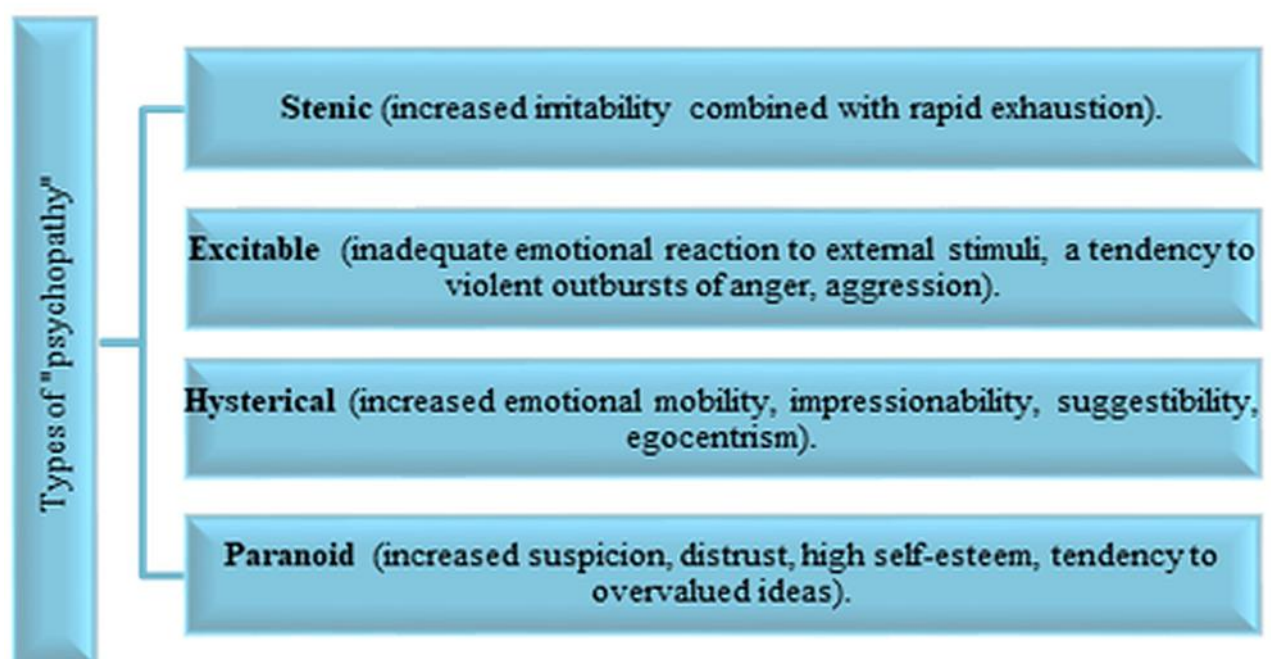

Fig. 3. Types of «psychopathy»

Persons with psychopathic and psychopathological character traits should not be allowed to work. This is implemented in psychological testing procedures.

For example, when selecting a job, one should take into account the type of higher nervous activity (HNA), because people with different types of HNA react differently to different stimuli. So, in choleric people, the nervous processes are characterized by the predominance of excitement over inhibition, it is difficult for such an employee to control his actions, therefore, the risk of industrial electrical injuries increases.

Stress is a significant risk factor. As you know, stress changes the electrical resistance of the skin. It can be from 2,000 ohms to $2,000,000 \mathrm{ohms}$. Skin resistance from 10,000 to $2,000,000 \mathrm{ohms}$. For comparison, internal organs and tissues have a resistance of only 500 to 1000 ohms.

The condition of the skin can significantly affect the nature of the electrical injury, as follows - what kind of skin was at the time of the injury, for example, if it is thick, dry, then the skin has great resistance. The moisture of the skin is of great importance - for example, the resistance of the skin moistened with water drops by $40 \%$.

The condition of the skin matters, which also depends on the state of the body as a whole - the state of the nervous, endocrine and other systems. Therefore, the resistance of the skin is not similar in different people, in areas of the human body [4].

According to foreign researchers, up to $20.3 \%$ of electricians experience stress in the workplace, especially those working on high voltage power grids.

Stress at work is a reaction to the presentation of demands on employees that do not correspond to their level of knowledge and skills, as well as the need to act in conditions of time pressure or lack of information. Occupational stress is a phenomenon expressed in mental and physical reactions to difficult situations of work activity. All personnel are exposed to stress, regardless of the amount of work, and in turn stress leads to a decrease in human performance.

We represent stress management in the form of Fig. 4. 


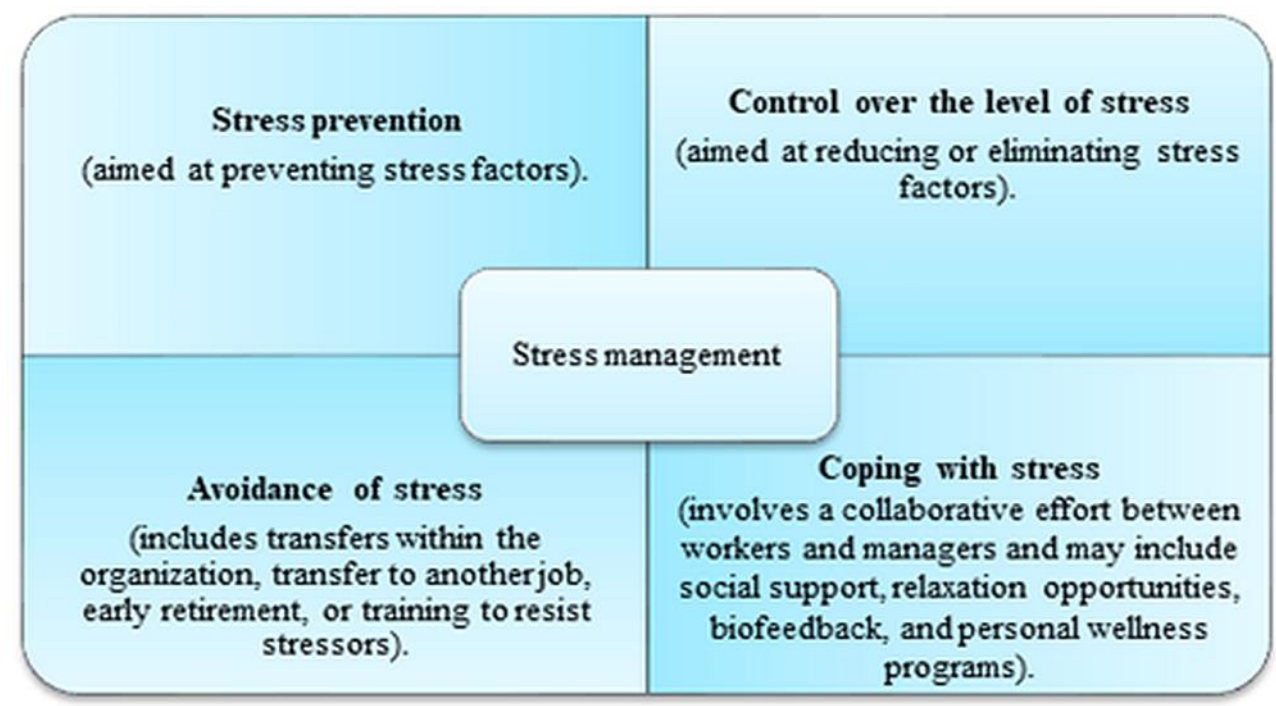

Fig. 4. Stress Management

\section{Discussion}

The data considered give directions in the development and planning of programs in the direction of occupational safety.

An important area of increasing security efficiency is the digitalization of the network, which cannot be successful without the implementation of the "Digital Electrician" concept. "Digital Electrician" is a concept of an organizational and hardware-software complex designed to increase the safety of work at power grid facilities and to automate the processes of their planning, execution and control.

Currently, the "Digital Electrician" project is being implemented in the electric power industry. The project is aimed at solving problems associated with violation of labor protection rules during work on operated electrical installations.

This project can also be implemented for electricians servicing electrical installations of a mining enterprise. The "Digital Electrician" project implies control, which is ensured thanks to:

- monitoring the employee on labor protection on a daily basis;

- visualization - psychological preparation of an employee to comply with labor protection requirements.

Monitoring of labor protection worker on a daily basis. The electrician turns on the phone, then enters the password (you can use the personnel number), is tested, where he needs to answer 3 questions with 3 answer options. If the answer is correct - admission to work is received, if an incorrect answer is given, admission to work is received, but the next day an additional question is displayed on the topic in which the mistake was made. At the end of the month, the direct supervisor analyzes the results of testing in order to identify weak knowledge identified by those employees, on the basis of which a technical training plan is formed.

Visualization - the psychological preparation of an employee to comply with labor protection requirements is that, before arriving at the place of work, the issuing work permit, allowing, the manufacturer of the work, team members, the slinger, the work cradle, the MKM driver, carry out visual psychological training, in part safety measures when performing future work specified in the work permit. For each category of workers, training 
is carried out, depending on the type of work they perform, and thereby actually prepares them for direct implementation.

The Digital Electrician project will speed up adaptation to new knowledge, which is highly relevant in the context of dynamically changing technologies in the electric power industry. Ultimately, the conscious perception of the concept of "Digital Electrician" reduces the desynchronization of mental and emotional processes of the electrician's body, increases its adaptive potential, and also helps to identify workers at risk. Reducing the volume of completed documentation frees up time for the employee to perform more creative tasks.

In terms of the influence of the "Digital Electrician" on psychophysiological indicators, the following should be noted. The use of inherently standard response algorithms contributes to a clearer performance of their duties by electricians. Such important psychophysiological characteristics as memory and attention with daily training will improve, or - in older age groups - will remain at the proper level.

Creation of a personalized digital workplace (with elements of training), with easy individual adjustment, in addition to a disciplining and motivating effect, can have a positive effect on the emotional state of an employee; we predict a decrease in the level of psycho-emotional stress of electricians.

In general, the effect of introducing the concept of "Digital Electrician" is shown in Figure 5 .

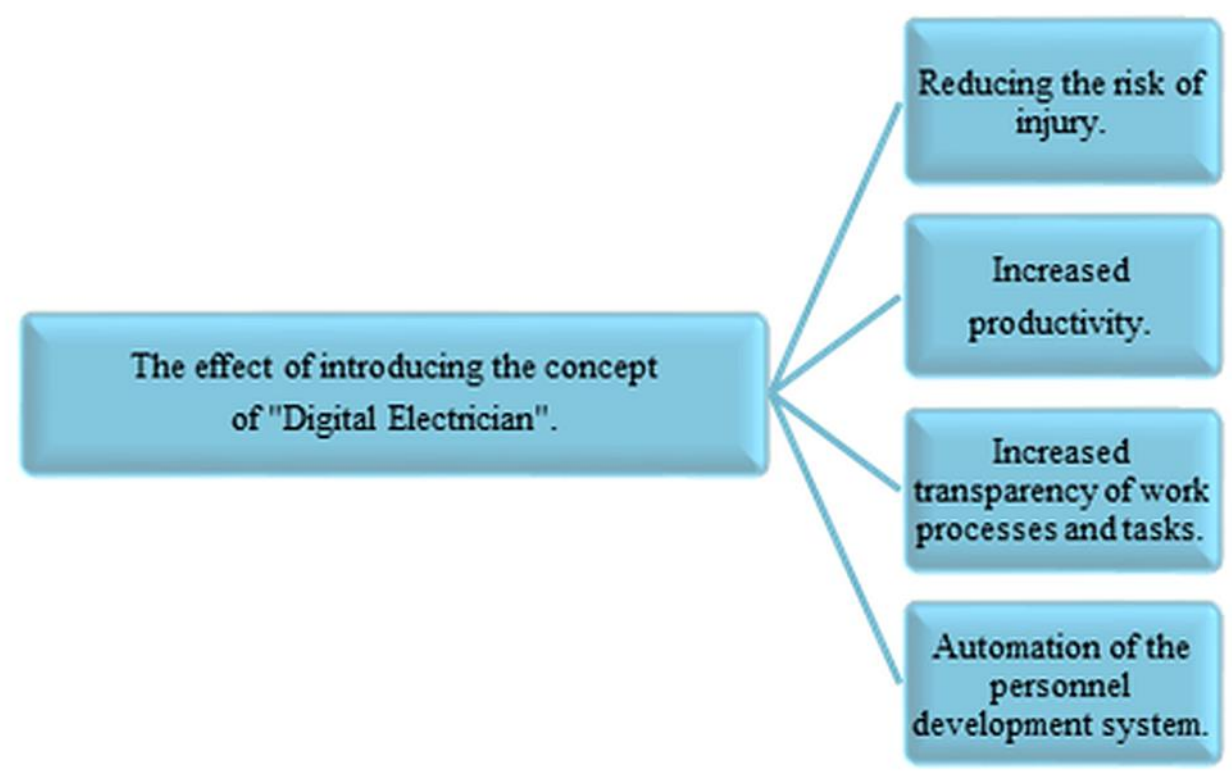

Fig. 5. The effect of implementing the concept of "Digital Electrician"

\section{Conclusion}

The approaches that are used in the electric power industry can also be applied when organizing the maintenance of the electrical facilities of a mining enterprise.

In conclusion, it should be noted that a systematic approach is important in ensuring the safety of personnel. Since the reduction of the negative influence of the human factor on the risk of injury is possible only if timely diagnosis and regular corrective and preventive work are provided. 


\section{References}

1. I.D. Grab, A.V. Zatlkin, V.B. Almametov, N.K. Yurkov, Proceedings of the International Symposium Reliability and Quality, 2, 435 (2010)

2. P.A. Dolin, Electrical safety: Theory and practice (MEI, Moscow, 2012)

3. O.V. Kochin, Medicine of emergency conditions, 8(71), 7 (2015)

4. B.I. Kudrin, B.V. Zhilin, Yu.V. Matyunina, Power supply of consumers and modes: study guide (P.H.MEI, Moscow, 2013)

5. Yu.V. Shcherbatykh, Psychology of stress (Eksmo, Moscow, 2006)

6. ElectronicsWorkbench.MultiSIM. Design and modeling (Russian branch of NationalInstruments Corporation, 2006)

7. H. Fischer, L. Kheifets, A. Huss, TL. Peters, R. Vermeulen, Epidemiology, 26(6), 824 (2015)

8. K. Grell, A. Meersohn, J. Schüz, C. Johansen, Bioelectromagnetics, 33 (6), 459 (2012)

9. A. Huss, A. Spoerri, M. Egger, H. Kromhout, R. Vermeulen, Amyotroph Lateral Scler Frontotemporal Degener, 16(1-2), 80 (2015) 